\title{
La gestion des flux d'azote et la localisation des cultures
}

\section{François Papy ${ }^{1}$ \\ Didier Picard ${ }^{2}$}

${ }^{1}$ 92, avenue Victor Hugo

92170 Vanves

France

<papy.francois@numericable.fr>

${ }^{2} 23$ rue des Réservoirs

78000 Versailles

France

$<$ diel.picard@wanadoo.fr $>$
Le dossier azote contenu dans ce numéro nous conduit à développer des principes de gestion des flux de cet élément qui remettent en cause un des traits majeurs de l'économie libérale : la localisation des productions marchandes selon leurs avantages comparatifs. Ce dossier, centré sur les systèmes de culture céréaliers, porte sur la fertilisation azotée qui a été un des principaux moteurs de la progression des rendements et la cause de dégradations environnementales : à l'échelle régionale par la pollution nitrique des eaux ; à l'échelle planétaire par l'accroissement des émissions de gaz à effet de serre. Un compromis entre performances productives et environnementales est à rechercher, sachant que l'efficacité productive de l'azote diminue avec l'augmentation de la dose, tandis qu'augmentent les effets environnementaux néfastes. À l'échelle de la parcelle on sait relativement bien ajuster la dose utilisée à des objectifs de rendement. Aussi, même si, par un pilotage très fin des apports successifs d'azote, on sait améliorer le compromis, la fixation de l'objectif de rendement est une des clés du problème. Une logique de production (fonction du rapport des prix entre azote et céréales et de l'assurance à prendre face aux aléas climatiques) incite à l'augmenter dans le contexte de prix des céréales élevés ; une logique environnementale à le diminuer. Cependant, même avec des objectifs de rendement relativement bas, les risques de pollution restent forts surtout lorsqu'ils s'additionnent dans les régions spécialisées dans la culture céréalière comme l'est le Bassin parisien.
Aussi, au-delà du dossier azote présenté dans ce numéro, se pose la question de savoir pourquoi cette spécialisation régionale; pourquoi une forte dominance des céréales dans le Bassin parisien tandis qu'en Bretagne, une forte concentration d'élevage industriel hors sol fait de cette région un puits d'azote par l'apport d'aliments concentrés qu'elle implique. La réponse est dans le principe de l'économie libérale de localisation des produits marchands dans les lieux où ils présentent, par rapport aux autres, un avantage comparatif. Dans une région donnée, seules subsistent les productions ayant un avantage comparatif par rapport à d'autres régions. Dans les deux cas cités plus haut (Bassin parisien et Bretagne) l'introduction excessive d'azote sous forme active dans les agrosystèmes (engrais ici, et là aliments concentrés) conduit à une pollution des eaux continentales et maritimes. Des alternatives existent pourtant qui consistent à diversifier les productions : introduction de prairies et d'élevage dans les régions céréalières; de céréales à paille dans les régions d'élevage industriel pour nourrir les animaux et recevoir leurs déjections. Les expériences qui vont dans ce sens montrent l'intérêt qu'elles présentent pour mieux gérer les flux d'azote. Mais la généralisation de solutions pratiques se heurte au poids des filières mises en place par la logique économique dominante de localisation des produits agricoles. Et les structures ainsi mises en place accentuent l'effet des avantages comparatifs. 
Enfin que dire, à l'échelle planétaire, du déséquilibre d'usage par l'agriculture, entre hémisphères Nord et Sud, des apports nets d'azote actif d'origine anthropique qui aboutit, in fine, à accroître les émissions de gaz à effet de serre. Il résulte encore d'un avantage comparatif, acquis progressivement et accentué au cours de l'histoire, des premiers pays industrialisés sur les autres, qui aboutit à détruire les agricultures les plus fragiles des pays du Sud. Ce n'est pas en forçant par la fertilisation azotée la production des agrosystèmes déjà bien productifs que l'on arrivera à nourrir la planète dont la population va encore croître, mais en augmentant les rendements là où les marges de progrès sont encore fortes (Afrique subsaharienne en particulier). C'est bien là qu'à dose faible des apports d'azote seraient les plus efficaces sur la production sans causer autant de dégâts environnementaux. C'est aussi là qu'ils seraient le plus nécessaires, étant donné les prévisions de croissance démographique de l'Afrique et de l'Asie et de stagnation des pays industrialisés.

Plus que toute autre activité humaine, l'agriculture est fortement liée à la gestion des cycles biogéochimiques, comme d'ailleurs à celle de la biodiversité. Plus que toute autre activité, l'agriculture a des impacts (positifs ou négatifs) sur la ressource en eau, la composition atmosphérique, la biodiversité... Aussi ne peut-elle être considérée de la même manière que les autres activités productives. Et pourtant c'est bien ce qui a été adopté en 1994 dans les accords de Marrakech instituant l'Organisation mondiale du commerce (OMC) dont les principes de l'économie libérale commandent la localisation des cultures et les modalités de conduite. Les négociateurs des différents accords de libre-échange qui se généralisent de par le monde en sont-ils bien conscients ? Ne serait-il pas temps de concevoir une organisation mondiale du commerce spécifique aux produits agricoles? 